\title{
Exacerbations in the pre- and post-COPD diagnosis periods
}

This article was published in the following Dove Press journal:

Pragmatic and Observational Research

30 April 2013

Number of times this article has been viewed

\author{
Barbara P Yawn' \\ Peter Wollan' \\ Matthew Rank ${ }^{2}$ \\ 'Department of Research, Olmsted \\ Medical Center, Rochester, MN,USA; \\ ${ }^{2}$ Division of Allergy, Asthma, and \\ Clinical Immunology, Mayo Clinic, \\ Scottsdale, AZ, USA
}

Purpose: Chronic obstructive pulmonary disease (COPD) is usually recognized in its later stages, delaying therapeutic opportunities. Screening questionnaires have modest sensitivities and specificities. Adding questions about prior respiratory events might improve screening characteristics.

Methods: Using administrative data from all health care facilities in Olmsted County, Minnesota USA, we identified all adults with an initial diagnosis of COPD from 2005 through 2007. For each individual we identified all coded lower and upper respiratory events in the 2 years before and the 2 years after the COPD diagnosis and categorized them as probable or possible COPD exacerbations.

Results: 356 women and 346 men $(\mathrm{N}=702)$ with a mean age of 67.5 years and 66.6 years respectively had a first diagnosis of COPD during the study period. Respiratory events in the 2 years prior to a COPD diagnosis were common with a range of 0 to 16 events per individual and a mean (SD) of 2.04 (2.14), 1.38 (1.86) all of which were probable COPD exacerbations. Prediagnostic respiratory events were predictive of similar events in the post diagnostic period (odds ratio $=1.6,95 \%$ confidence interval $[\mathrm{CI}] 1.3$ to 1.8 ).

Conclusion: Inquiring about the number and type of upper or lower respiratory events in the 2 past years may be a useful addition to the "screening" criteria to improve COPD identification, especially those at risk of frequent exacerbations.

Keywords: pulmonary disease, chronic obstructive, mass screening, case finding, exacerbations, respiratory tract infections

\section{Introduction}

Chronic obstructive pulmonary disease (COPD) is common, affecting up to $5 \%-8 \%$ of adults, primarily those over age 45 who are current or former smokers. ${ }^{1-4}$ Advances in therapies over the past decade can improve the COPD patient's quality of life, functional status, decrease exacerbations and, in the case of oxygen and smoking cessation, increase longevity. ${ }^{5-8}$ While awareness of COPD has increased in the past decade, COPD remains under-diagnosed and inadequately treated. ${ }^{2,9}$

Early diagnosis of COPD remains challenging. Universal spirometry screening for COPD identification is not recommended. ${ }^{10}$ Age, and being a current or former smoker are insufficient to serve as risk factors warranting spirometry evaluation since $60 \%$ to $80 \%$ of long term smokers will not develop COPD. ${ }^{11}$ To overcome this gap in identifying sufficient risk to warrant diagnostic evaluation, several COPD screening or case finding survey tools have been developed. ${ }^{12-14}$ The sensitivity, specificity, and positive predictive value of the COPD-Population Screener (COPD-PS) ${ }^{12}$ and
Correspondence: Barbara P Yawn Department of Research, Olmsted Medical Center, 210 9th Street SE, Rochester, MN 55904, USA

Tel + I 5072872758

Fax + I 5072872722

Email byawn@olmmed.org
Pragmatic and Observational Research 2013:4 I-6

(C) 2013 Yawn et al, publisher and licensee Dove Medical Press Ltd. This is an Open Access article which permits unrestricted noncommercial use, provided the original work is properly cited.
Dovepress

http://dx.doi.org// 0.2147/POR.S41778 
the Lung Function Questionnaire (LFQ) ${ }^{13}$ are better than the use of age and smoking status alone but fall short of a sensitivity rate desirable for a screening tool. This study is intended to explore another potential "risk" factor that might be included in the next generation of COPD screening tools. Just as children often have multiple respiratory events prior to being recognized and diagnosed with asthma, ${ }^{15}$ older adults may have similar increases in respiratory events prior to their first COPD diagnosis. If true, frequency of respiratory events could be added as a domain in the next generation COPD case finding or screening tools. The history of frequent prediagnosis exacerbations may also help predict the COPD "frequent exacerbators", a category of special interest. ${ }^{16}$

\section{Methods}

\section{Overview}

This is a retrospective study using administrative and medical records data. Using the resources of the Rochester Epidemiology Project (REP), all individuals who had a first diagnosis of COPD from January 1, 2005 through December 31, 2007 were identified using ICD-9 codes for chronic bronchitis, emphysema or COPD (Table 1). Patients with other chronic lung diseases such as idiopathic pulmonary fibrosis (IPF), lung cancer and asthma diagnostic codes during the two years prior to the first COPD diagnosis were excluded. While this may have excluded some individuals with COPD who were labeled as asthma, the objective of the study was to assess new COPD cases without prior therapy for any obstructive lung disease.

The Rochester Epidemiology Project (REP) is a National Institutes of Health funded data linkage and storage system

Table I ICD-9 codes used as diagnoses of interest

\begin{tabular}{|c|c|}
\hline \multicolumn{2}{|l|}{ Definition of COPD diagnosis } \\
\hline \multicolumn{2}{|c|}{ One or more visits with any of following ICD-9 codes in 2006-2007 } \\
\hline \multicolumn{2}{|l|}{$491.2 x x$} \\
\hline \multicolumn{2}{|l|}{$492 \times x$} \\
\hline \multicolumn{2}{|l|}{496} \\
\hline \multicolumn{2}{|l|}{ Respiratory illness visit codes } \\
\hline \multicolumn{2}{|l|}{ Probable COPD exacerbations } \\
\hline Wheezing & 786.07 \\
\hline COPD exacerbation & 491.21 \\
\hline Bronchitis & 466.xx or $490 . x x$ \\
\hline Pneumonia/pneumonitis/influenza & $480-488$ \\
\hline Burst of oral steroids & From e-prescribing data \\
\hline $\begin{array}{l}\text { Emergency room or hospitalization } \\
\text { for respiratory event }\end{array}$ & $\begin{array}{l}\text { From local codes developed } \\
\text { in billing for site of visit }\end{array}$ \\
\hline \multicolumn{2}{|l|}{ Possible COPD exacerbations } \\
\hline Coughing & 786.2.xx \\
\hline URI & 462.xx or $461 . x x$ or $465 . x x$ \\
\hline
\end{tabular}

Abbreviations: COPD, chronic obstructive pulmonary disease; URI, upper respiratory infection. that maintains all diagnostic and laboratory information for all individuals who make visits to any medical facility within Olmsted County, MN. ${ }^{17-19}$ There are currently two large integrated health care systems (the Olmsted Medical Center and the Mayo Clinic) that include multiple outpatient offices, three emergency departments and three hospitals within the county. An additional solo physician sees outpatients only.

The REP uses a unique person identifier to link each individual in the county with all diagnoses they have been given and all visits at all health care facilities within the county. ${ }^{19}$ It is therefore possible to determine everyone who had a visit with a diagnostic code for COPD during the time period of interest and ensure that they have not had a COPD diagnostic code at any previous visit. Over $95 \%$ of the people of Olmsted County have not refused the research authorization required by Minnesota statute and therefore the REP provides a true community population sample from which the COPD cases were identified. ${ }^{20}$

The REP administrative data were used to identify all visits with respiratory codes during the 2 years prior to the first COPD diagnosis and the 2 years after the first COPD diagnosis. Because most COPD diagnoses are made at the time of a respiratory event, ${ }^{21}$ the diagnostic visit for COPD was included as a major respiratory event in the "before" period. During the 2 years after the initial COPD diagnosis, visits with a COPD diagnosis but no other respiratory event diagnosis (eg, bronchitis or COPD exacerbation) were not included as probable or possible exacerbation visits which may have led to an underestimate of respiratory event. Probable COPD exacerbations were classified as lower respiratory symptoms codes including wheezing, COPD exacerbation, bronchitis, and pneumonia. In addition a burst of oral steroids or an emergency department/hospital visit for a respiratory event were categorized as probable COPD exacerbations. A possible COPD exacerbation included diagnostic codes for coughing or upper respiratory tract infection (See Table 1 for summary of codes and classification).

Individuals with obstructive lung disease often have "prolonged episodes" of respiratory problems such as colds or bronchitis. ${ }^{21}$ To ensure that such episodes were not double counted, health care utilization was combined into episodes of respiratory care lasting 28 days each.

\section{Data analysis}

Simple descriptive statistics were used to assess the range, mean, and first and third quartiles of respiratory event frequency. The top three diagnostic categories were calculated from assessing the percent of each type of diagnosis given 
during the 2 years before and the 2 years after first COPD diagnosis. The initial COPD diagnosis was included in "before" period. Respiratory event rates were reported for both probable COPD exacerbation and those with possible COPD exacerbations as well as all events combined. Results are reported both with and without adjustments for age and sex. Frequencies were compared using Chi-squared statistics or Wilcoxon rank-sum tests and the change in number of episodes in the 2-year periods pre- and post-diagnosis was compared using logistic regression.

\section{Results}

A total of 702 patients were identified with new diagnoses of COPD: 356 women and 346 men (mean ages 67.5 and 66.6 years respectively). An additional group of 229 people had a single diagnostic code for COPD with no respiratory event or COPD related codes in the previous or following 2 years. These patients were not included in further analysis since it seems less likely they actually have COPD.

In the 2 years before diagnosis the subjects experienced a range of 1 to 16 respiratory events with a mean of 2.04 events per the 2 years (SD 2.14 and mean of 2.29 and 1.78 for women and men respectively, $P=0.002$ ). Events consistent with probable COPD exacerbation had a mean of 1.38 visits for the 2 years. The number of episodes was highly skewed. The twenty-fifth percentile for number of respiratory episodes was 1 and the seventy-fifth was 2, implying that only a few individuals had 3 or more episodes (Figures 1 and 2). In the
2 years prior to their first COPD diagnosis the most common respiratory diagnosis was cough and upper respiratory infection (URI) (mean of 0.66 episode) followed by use of oral steroids (mean of 0.66 episodes per person) followed by pneumonia requiring hospitalization (mean of 0.41 episodes per person). For each of the types of events, the mean number of events in the 2 years was higher for women than for men.

In the 2 years after the COPD diagnosis, this same group of individuals experienced a range of 0 to 28 respiratory events. When all respiratory events were included, the mean was 2.60 (SD 2.86) with a higher mean rate in women than in men (2.76 and 2.42 respectively, $P=0.03$ ). Limiting the events to probable COPD exacerbations the mean (SD) was 1.9 (1.9). The data remained skewed with the twenty-fifth percentile being 0 episodes and the seventy-fifth being 2 . The rate of probable COPD exacerbations was lower in the 2 years prior to the COPD diagnosis compared to the 2 years after (mean 1.38 vs $1.9, P<0.0001$ ) as was the overall rate of respiratory events $(2.04$ vs $2.60, P<0.0001)$. After the diagnosis of COPD, the most common event was use of oral steroids (mean of 0.91 episodes) followed by pneumonia requiring hospitalization (mean 0.70 episodes per person) and upper respiratory events (mean also 0.70 events per person).

The overall rates of before and after events are shown in Figure 1 for all respiratory events and in Figure 2 for the probable COPD exacerbations. We used logistic regression to assess whether or not prediagnostic events (those that might

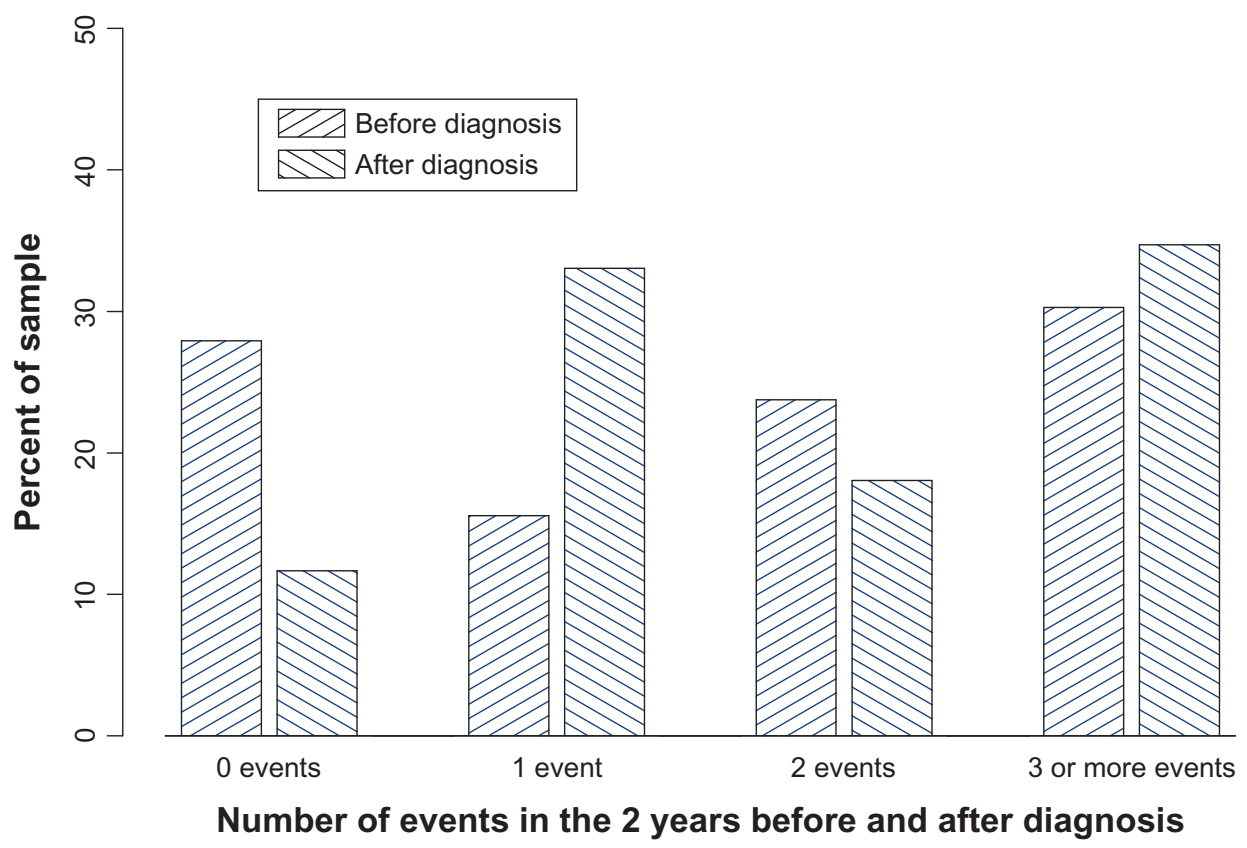

Figure I All respiratory events 2 years before and after COPD diagnosis. 


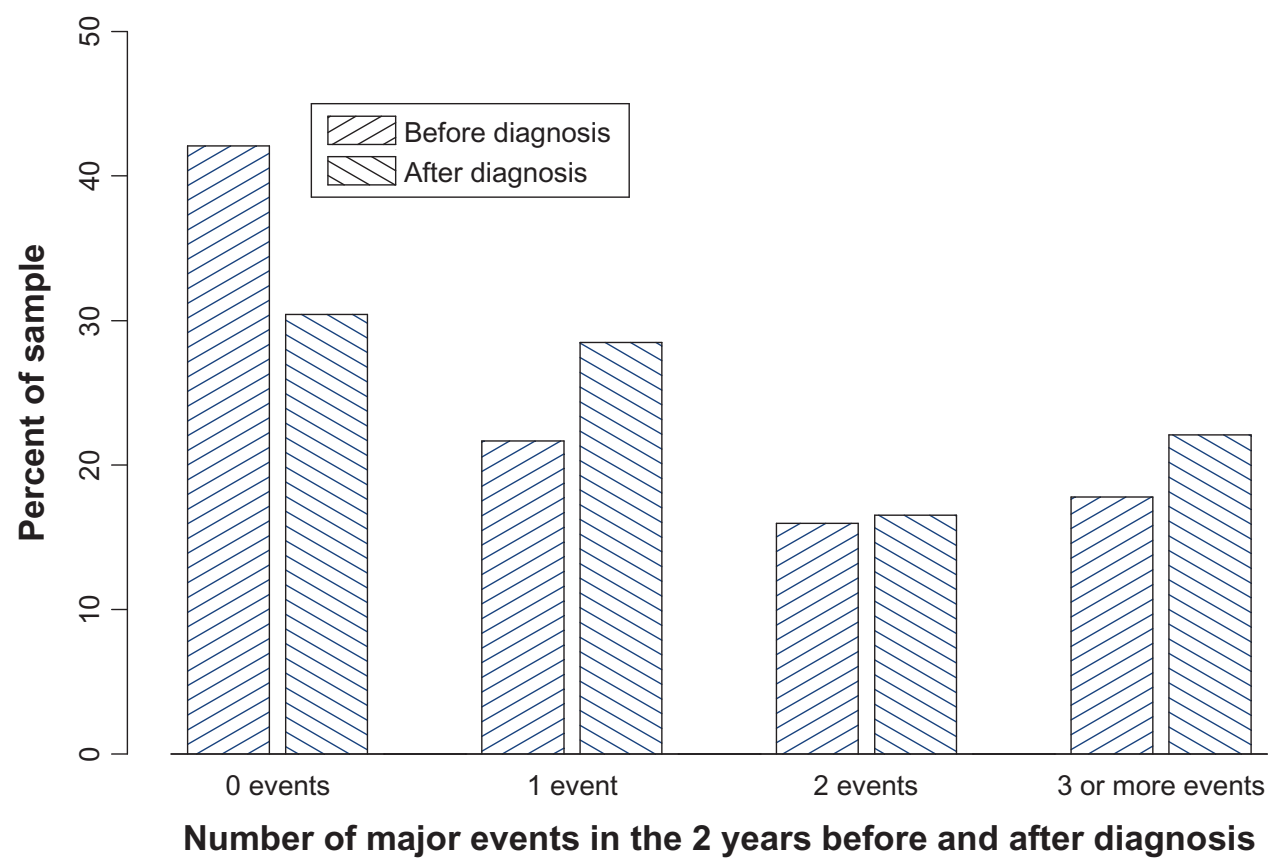

Figure 2 Lower respiratory events (not cough or URI) in 2 years before and after COPD diagnosis. Abbreviations: COPD, chronic obstructive pulmonary disease; URI, upper respiratory infection.

be identified at screening) predict post diagnostic events. We were especially interested in who had three or more episodes in the 2-year periods before or after diagnosis, individuals who would fit into the frequent exacerbator category. ${ }^{16}$ The odds ratio of having three or more post diagnosis episodes was 1.6 (CI 95\% 1.3 to 1.8) for those with any three or more prediagnostic episodes. Limiting to only the lower respiratory event dropped the odds ratio to 1.3 (CI 95\% 1.1, 1.6) but it remained statistically significant (Table 2 ).

\section{Discussion}

Among this group of men and women with a first diagnosis of COPD, about one third had two or more major respiratory episodes in the 2 years prior to recognition and diagnosis of their COPD. This is higher than the rates of these major respiratory events such as bronchitis and pneumonia among the general population of adults 45 years and older. ${ }^{21,22}$ It also

Table 2 Number and rate of prediagnostic lower respiratory events by study

\begin{tabular}{|c|c|c|c|c|c|c|c|c|}
\hline \multirow[t]{2}{*}{ Study } & \multicolumn{2}{|c|}{ No events } & \multicolumn{2}{|c|}{ I event } & \multicolumn{2}{|c|}{2 events* } & \multicolumn{2}{|c|}{$\begin{array}{l}3 \text { or more } \\
\text { events* }\end{array}$} \\
\hline & $\mathbf{n}$ & $\%$ & $\mathbf{n}$ & $\%$ & $n$ & $\%$ & $\mathrm{n}$ & $\%$ \\
\hline $\begin{array}{l}\text { Suruki et a }{ }^{25} \\
N=19,172\end{array}$ & 11,153 & 58.2 & 4545 & 23.7 & 1826 & 9.5 & 1.648 & 8.6 \\
\hline $\begin{array}{l}\text { Yawn et a }\left.\right|^{2} \\
N=703\end{array}$ & 298 & 42.3 & 155 & 22.1 & 121 & 17.2 & 129 & 18.4 \\
\hline
\end{tabular}

Note: *Event rate is different $P<0.05$. appears to be higher than among adult smokers without diagnosed COPD. ${ }^{23}$ Therefore, this may be an additional criteria to add to the COPD screening questionnaire. In addition, a question regarding frequent exacerbations may help to identify those more likely to be "frequent exacerbators" at least 1 year earlier and therefore lead to more aggressive earlier therapy. ${ }^{23}$

Many studies show that on average people with COPD are diagnosed only after they have lost $50 \%$ or more of their lung function as assessed by forced expiratory volume in the first second of expiration $\left(\mathrm{FEV}_{1}\right){ }^{24}$ Since most COPD patients are symptomatic and up to one third have exacerbations prior to reaching the level of an $\mathrm{FEV}_{1}$ of $50 \%$ of predicted, ${ }^{5}$ it is not surprising that many of the individuals we studied had multiple upper and lower respiratory events prior to their first COPD diagnosis. In a poster presented at the 2010 American Thoracic Society (ATS) meeting, Suruki et al used data from the UK primary care registry to identify new diagnosis of COPD and similar to our study, used diagnostic codes to identify respiratory events in the 24 months prior to diagnosis. They included only "lower respiratory events" ${ }^{25}$ At all levels of events from 0 to 3 or more in the 2 years, women were more likely to have an event as confirmed by our data. The rates of $0,1,2$, and 3 or more events are very similar in their data and ours (Table 2) again confirming that our data are representative of primary care population respiratory event rates for people with COPD. The data from our study may 
be more likely to capture people with 2 or 3 events since we captured oral steroid bursts and hospitalizations that may not have the respiratory event listed among the codes which both we and Suruki included. ${ }^{25}$ Suruki study did not collect information on post-diagnosis events. In our data, the rate of any event and lower respiratory events was higher in the post-diagnosis period compared with the prediagnosis period in the same group of individuals. This increase in the post-diagnosis period may represent increased disease or an increased awareness of the importance of treating respiratory events aggressively such as demonstrated by the increased rate or oral steroid use.

Currently COPD remains under-diagnosed with significant interest in developing tools to improve earlier diagnosis and screening or case finding. Several symptom based screening questionnaires have been developed and assessed in primary care. The COPD-PS ${ }^{12}$ tool was designed to be an awareness raising tool and perhaps a population screener. The scoring for screen failure was based on a balance of sensitivity and specificity, not the usual epidemiological strategy of developing cut points based on high sensitivity while maintaining specificity in ranges of $80 \%$ or greater. Specificity is reported as $38.3 \%$ with sensitivity rates close to $80 \%$.

Recently, Yawn et al validated another tool designed for screening within primary care practices and scored to maximize sensitivity while retaining specificity of at least $85 \% .{ }^{13}$ When tested in real world primary care practices the tool had a sensitivity of $82.6 \%$; but specificity of only $47.8 \%$ with $54.3 \%$ correctly classified as either COPD or not COPD based on pre- and post-bronchodilator spirometry and the GOLD criteria. ${ }^{13}$ Price et al ${ }^{14}$ developed and tested a tool in primary care patients in the UK. The eight-item questionnaire was reported to perform well in UK primary care practices with a sensitivity of $80.4 \%$ and specificity of $72.0 \%$ with positive predicative values of $30 \%$ and negative predicative values of $71 \% .{ }^{14}$ When testing was repeated in a Dutch and Belgian population Kotz et $\mathrm{al}^{23}$ reported sensitivities of $65.8 \%$ and $89.2 \%$ (depending on cut-off values) with corresponding specificities of $54.0 \%$ and $24.4 \%$, much lower than reported in the UK.

None of the COPD screening surveys have reported sensitivities of over $90 \%$ and reported specificities seldom reach $50 \%$. Therefore, additional questions or procedures need to be added to these tools before they can be recommended for widespread COPD screening (http://www. uspreventiveservicestaskforce.org/uspstf/uspscopd.htm). A question about respiratory events in the 1 to 2 years before the date of screening maybe helpful in improving specificity and helping identify frequent exacerbators at the time of diagnosis. This approach requires further evaluation and testing in pragmatic trials.

Recent work in COPD phenotypes has identified a group of frequent exacerbators ${ }^{23}$ that may have a more rapidly progressive course of COPD and might benefit from aggressive initial therapy. Our results showed that the number of respiratory events in the 2 years before the COPD diagnosis predicted an increased risk of continued exacerbations post diagnosis. Therefore, the addition of a question about respiratory events in the 2 years prior diagnosis may help identify the phenotype of frequent exacerbators at the time of first diagnosis which may be very important even if the addition of the number of respiratory events in the previous 2 years does not increase the sensitivity of the case finding or screening tools. The result of greater numbers of exacerbations identified post diagnosis seems counterintuitive since COPD therapy is reported to decrease exacerbations. ${ }^{7,8}$ However, our definition of exacerbations included the use of 5 or more days or oral steroids which may be used more commonly for lesser respiratory concerns once the diagnosis of COPD is made. In addition, progression of COPD can be accompanied by increased rates of exacerbations. . $^{5,622-24}$

Our study has limitations. We used administrative data with limited confirmation from medical record review. Specifically, we did not require diagnostic spirometry. This prevents any assessment of the accuracy of the COPD diagnosis other than removing people from the group who had no additional respiratory events or visits in the 2 years before and the 2 years after the initial COPD administrative code. The COPD diagnoses are all based on physician coding. Therefore, some of these patients may not actually have COPD but are being treated as if they do. Finally, we used national data for the comparator rates of respiratory events in the general population and in smokers. These estimates may not be applicable to our population.

\section{Conclusion}

About $35 \%$ of people with a new diagnosis of COPD have had two or more lower respiratory events in the 2 years immediately preceding their COPD diagnosis. Therefore, adding a question about recent upper and lower respiratory events may improve the screening characteristics of current survey COPD screening tools. Knowledge of frequent respiratory events prior to a COPD diagnosis may also help 
classify individuals as being in the "frequent exacerbator" phenotype. Additional research and pragmatic evaluation are required.

\section{Acknowledgments}

This study was funded by Novartis from an investigator initiated grant and from the National Institute of Aging, National Institute of Health (R01-HS 30567).

\section{Disclosure}

The authors have no conflicts of interest to declare in this work.

\section{References}

1. Lung.org [homepage on the Internet]. American Lung Association. Epidemiology and statistics unit. Research and program services division. Trends in COPD (chronic bronchitis and emphysema): morbidity and mortality. Feb 2010. Available from: http://www.lungusa.org. Accessed November 22, 2010.

2. Yawn B, Mannino D, Littlejohn T. Prevalence of COPD among symptomatic patients in a primary care setting. Curr Med Res Opin. 2009;25:2671-2677.

3. Buist AS, Vollmer WM, Sullivan SD, et al. The burden of obstructive lung disease initiative (BOLD): rationale and design. COPD. 2005;2: 277-283.

4. Buist AS, McBurnie MA, Vollmer WM, et al; BOLD Collaborative Research Group. International variation in the prevalence of COPD (The BOLD Study): a population-based prevalence study. Lancet. 2007;370: 741-750

5. Goldcopd.org [homepage on the Internet]. Global Initiative for Chronic Obstructive Lung Disease. Global strategy for the diagnosis, management, and prevention of chronic obstructive pulmonary disease. 2009. Available from: http://www.goldcopd.org/guidelinesresources. asp?I12\&I2=0. Accessed October 27, 2010.

6. Celli BR, MacNee W. ATS/ERS Task Force. Standards for the diagnosis and treatment of patients with COPD: a summary of the ATS/ERS position paper. Eur Respir J. 2004;23:932-946.

7. Decramer M, Celli B, Kesten S, et al; UPLIFT Investigators. Effect of tiopropium on outcomes in patients with moderate chronic obstructive pulmonary disease (UPLIFT): a prespecified subgroup analysis of a randomised controlled trial. Lancet. 2009;374:1171-1178.

8. Jenkins CR, Jones PW, Calverly PMA, et al. Efficacy of salmeterol/ fluticasone propionate by GOLD stage of chronic obstructive pulmonary disease: analysis from the randomised, placebo-controlled TORCH study. Respir Res. 2009;10:59.
9. Buffels J, Degryse J, Heyrman J, Decramer M. Office spirometry significantly improves early detection of COPD in general practice: the DIDASCO Study. Chest. 2004;125:1394-1399.

10. US Preventive Services Task Force. Screening for chronic obstructive pulmonary disease using spirometry: US Preventive Services Task Force recommendation statement. Ann Intern Med. 2008;148:529-534.

11. Tinkelman DG, Price DB, Nordyke RJ, Halbert RJ. COPD screening efforts in primary care: what is the yield? Prim Care Respir $J$. 2007;16:41-48.

12. Martinez FJ, Raczek AE, Seifer FD, et al; COPD-PS Clinician Working Group. Development and initial validation of a self-scored COPD population screener questionnaire (COPD-PS). COPD. 2008;5:85-95.

13. Yawn BP, Mapel DW, Mannino DM, et al; Lung Function Questionnaire Working Group. Development of the lung function questionnaire (LFQ) to identify airflow obstruction. Int J Chron Obstruct Pulmon Dis. 2010;5:1-10.

14. Price DB, Tinkelman DG, Halbert RJ, et al. Symptom-based questionnaire for identifying COPD in smokers. Respiration. 2006;73(3):285-295.

15. Ohar JA, Sadeghnejad A, Meyers DA, et al. Do symptoms predict COPD in smokers? Chest. 2010;137:1345-1353.

16. Macklem PT. Susceptibility to exacerbation in COPD. $N$ Engl J Med. 2010;363:2670; author reply 2671.

17. Kurland LT, Molgaard CA. The patient record in epidemiology. Sci Am. 1981;245:54-63.

18. Melton LJ. History of the Rochester Epidemiology Project. Mayo Clin Proc. 1996;71:266-274.

19. St Sauver JL, Grossardt BR, Yawn BP, Melton LJ, Rocca WA. Use of a medical records linkage system to enumerate a dynamic population over time: the Rochester epidemiology project. Am J Epidemiol. 2011;173: 1059-1068.

20. Yawn BP, Yawn RA, Geier GR, Xia Z, Jacobsen SJ. The impact of requiring patient authorization for use of data in medical records research. J Fam Pract. 1998;47:361-365.

21. Freid VM, Prager K, MacKay AP, Xia H. Chartbook on Trends in Health of Americans. Hyattsville, Maryland: National Center for Health Statistics. Health, United States. 2005:235.

22. Prager K, Fried VM, Xia H, MacKay AP. Chartbook on Trends in Health of Americans. Hyattsville, Maryland: National Center for Health Statistics. Health, United States. 2003:247.

23. Kotz D, Nelemans P, van Schayck CP, Wesseling GJ. External validation of a COPD diagnostic questionnaire. Eur Respir J. 2008;31:298-303.

24. Yawn BP, Keenan JM. COPD - the primary care perspective: addressing epidemiology, pathology, diagnosis, treatment of smoking's multiple morbidities and the patient's perspective. COPD. 2007;4:67-83.

25. Suruki R, East L, Cockle S, Toms M, Sampson T, Davis K. Examination of the Occurrence of Actue Respiratory Events During the 24 Months Prior to COPD Diagnosis. Am J Respir Crit Care Med. 2010;181:A6558.
Pragmatic and Observational Research

\section{Publish your work in this journal}

Pragmatic and Observational Research is an international, peer-reviewed, open access journal that publishes data from studies designed to reflect more closely medical interventions in real-world clinical practice compared with classical randomized controlled trials (RCTs). The manuscript management system is completely online and includes a very quick and fair peer-review

\section{Dovepress}

system. Visit http://www.dovepress.com/testimonials.php to read real quotes from published authors. 